Ankündigung eines Symposions

\title{
"The Turn of the Century. From Modernism to the Avant-garde in European Literature and the Arts Le Tournant du siècle. Du modernisme à l'avant-garde dans la littérature et les arts européens"
}

Universität Antwerpen, Literaturwissenschaftliche Abteilungen Antwerpen, 21.-23. Mai 1992

Ziel dieser Tagung ist, das Konzept des Modernismus und seine Bedeutung für die heutige Literatur und Kultur im Detail darzustellen und die terminologischen Probleme zu erläutern.

Es werden drei Themenkreise unterschieden:

1. Terminologie und Theorie: Identifizierung und Situierung des Phänomens Modernismus.

2. Perioden (Fin-de-siècle), Bewegungen (Naturalismus, Symbolismus,...), Strömungen (Avant-garde), Stile (Impressionismus, Art nouveau, ...) und individuelle Autoren und Texte in ihrem Verhältnis zum Modernismus.

3. Interdisziplinäre Aspekte: Vergleich zum modernistischen Ausdruck in den sonstigen Künsten.

Dauer der englischen oder französischen Referate: 30 Minuten. Bitte schicken Sie Ihre Vorschläge (1 bis 2 Seiten) vor dem 1. September 1991 an den Sekretär des Symposions: Dr. Luc Herman, Departement Germaanse Filologie, Universitaire Instelling Antwerpen, Universiteitsplein 1, B 2610 Antwerpen (Wilrijk), Belgien (Fax: 323-820 22 44). 